\section{QPP}

1. Serviço de Endocrinologia e Metabologia - SEMPR - Hospital de Clínicas, Universidade Federal do Paraná, Curitiba, Brasil.

2. Programa de Pós-Graduação em Medicina Interna, Departamento de Medicina Interna, Universidade Federal do Paraná, Curitiba, Brasil.

3. Serviço de Pneumologia, Hospital de Clínicas, Universidade Federal do Paraná, Curitiba, Brasil.

Submitted: 27 February 2015 Accepted: 14 July 2015.

Study carried out in the Serviço de Pneumologia and in the Serviço de Endocrinologia e Metabologia - SEMPR Hospital de Clínicas, Universidade Federal do Paraná, Curitiba, Brasil.

\title{
Sarcopenia in COPD: relationship with COPD severity and prognosis
}

\author{
Tatiana Munhoz da Rocha Lemos Costa ${ }^{1,2}$, Fabio Marcelo Costa ${ }^{3}$, \\ Carolina Aguiar Moreira ${ }^{1,2}$, Leda Maria Rabelo³ , César Luiz Boguszewski', \\ Victória Zeghbi Cochenski Borba',2
}

\begin{abstract}
Objective: To evaluate the prevalence of sarcopenia in COPD patients, as well as to determine whether sarcopenia correlates with the severity and prognosis of COPD. Methods: A cross-sectional study with COPD patients followed at the pulmonary outpatient clinic of our institution. The patients underwent dual-energy X-ray absorptiometry. The diagnosis of sarcopenia was made on the basis of the skeletal muscle index, defined as appendicular lean mass/height ${ }^{2}$ only for low-weight subjects and adjusted for fat mass in normal/overweight subjects. Disease severity (COPD stage) was evaluated with the Global Initiative for Chronic Obstructive Lung Disease (GOLD) criteria. The degree of obstruction and prognosis were determined by the Body mass index, airflow Obstruction, Dyspnea, and Exercise capacity (BODE) index. Results: We recruited 91 patients (50 females), with a mean age of $67.4 \pm 8.7$ years and a mean BMI of $25.8 \pm 6.1 \mathrm{~kg} / \mathrm{m}^{2}$. Sarcopenia was observed in $36(39.6 \%)$ of the patients, with no differences related to gender, age, or smoking status. Sarcopenia was not associated with the GOLD stage or with $\mathrm{FEV}_{1}$ (used as an indicator of the degree of obstruction). The BMI, percentage of body fat, and total lean mass were lower in the patients with sarcopenia than in those without $(p<0.001)$. Sarcopenia was more prevalent among the patients in BODE quartile 3 or 4 than among those in BODE quartile 1 or 2 ( $p=$ 0.009). The multivariate analysis showed that the BODE quartile was significantly associated with sarcopenia, regardless of age, gender, smoking status, and GOLD stage. Conclusions: In COPD patients, sarcopenia appears to be associated with unfavorable changes in body composition and with a poor prognosis.
\end{abstract}

Keywords: Sarcopenia; Body composition; Pulmonary disease, chronic obstructive; Severity of illness index.

\section{INTRODUCTION}

It is well known that COPD is a highly prevalent disease, affecting up to $10 \%$ of adults over the age of 40 , with high rates of morbidity and mortality. ${ }^{(1)}$ It is associated with various extrapulmonary disorders, such as cardiovascular disease, osteoporosis, cachexia, and anemia. Previous studies have indicated an association between low BMI and shorter survival in COPD patients. ${ }^{(2,3)}$ However, more recent data demonstrate that specific unfavorable changes in body composition, especially a decrease in lean mass, can be more reliable predictors of mortality than is low BMI alone. ${ }^{(4,5)}$ In patients with COPD, such changes have been shown to be related to exercise intolerance, impaired quality of life, and increased mortality. ${ }^{(6)}$ Few studies in the literature have correlated the prevalence of sarcopenia with indices of COPD severity. In addition, to date, there have been no studies correlating sarcopenia with the prognosis of COPD or correcting sarcopenia by the BMI to avoid misdiagnosis in overweight patients.

In COPD patients over 50 years of age, there is a reduction of $1-2 \%$ per year in muscle mass. ${ }^{(4)}$ In addition, among those in the 50- to 60-year age group and those over 60 years of age, muscle force has been shown to decline by $1.5 \%$ and $3.0 \%$ per year, respectively. ${ }^{(4)}$ This phenomenon, known as sarcopenia, is an important indicator of frailty syndrome. Sarcopenia has been shown to occur in approximately $5-13 \%$ of all individuals over 65 years of age, ${ }^{(7)}$ as well as in $20-40 \%$ of all COPD patients, which might include even the $10-15 \%$ of COPD patients who are of normal weight. ${ }^{2}$

In patients with COPD, a decrease in exercise capacity is the main factor limiting activities of daily living and is directly related to an increased risk of exacerbations. ${ }^{(8)}$ It has been suggested that such a decrease is the best predictor of early mortality in COPD. ${ }^{(3)}$ The degree of exercise capacity impairment (exercise intolerance), which results from factors such as impaired pulmonary function, limitation of gas exchange, and skeletal muscle dysfunction, is related to COPD severity. In the presence of dyspnea, such alterations lead to further impairment of physical activity, initiating a vicious cycle, also known as a downward spiral. ${ }^{(6,8)}$

The aim of this study was to evaluate the prevalence of sarcopenia in COPD patients. We also attempted to determine whether sarcopenia correlates with indices of COPD severity and with its prognosis. 


\section{METHODS}

\section{Patients and procedures}

This was a cross-sectional study involving 96 consecutive COPD patients, all over 50 years of age, treated at the Pulmonary Outpatient Clinic of the Federal University of Paraná Hospital de Clínicas, in the city of Curitiba, Brazil, between January of 2010 and December of 2011. The diagnosis of COPD was made on the basis of the Global Initiative for Chronic Obstructive Lung Disease (GOLD) criteria $^{(9)}$ : persistent progressive airflow limitation; and an increased chronic inflammatory response to noxious particles or gases in the airways and lungs, as evidenced by a post-bronchodilator $\mathrm{FEV}_{1} / \mathrm{FVC}$ ratio $<0.70$ on spirometry. ${ }^{(9)}$ The inclusion criteria were having smoking-related COPD, having undergone pulmonary function testing with a spirometer (KoKo PFT; nSpire Health, Longmont, CO, USA), and having a post-bronchodilator $\mathrm{FEV}_{1} / \mathrm{FVC}$ ratio $<0.70$. We excluded patients for whom any of the required test results were unavailable, as well as those who were taking drugs that can reduce lean mass and those who had any other disease known to affect body composition. The study was approved by the Hospital de Clínicas Ethics Committee on Human Research, and all participating patients gave written informed consent.

We collected clinical data, including lifetime smoking history, quantified in pack-years ${ }^{(10)}$; history of exacerbations in the last year; $\mathrm{FEV}_{1}$; the modified Medical Research Council dyspnea scale score(11); the score on the COPD Assessment Test, which quantifies the overall impact that COPD has on health status ${ }^{(12)}$; and the six-minute walk distance. ${ }^{(13)}$

The patients were classified by the percentage of predicted $\mathrm{FEV}_{1}$ (i.e., the degree of obstruction): $\geq 80 \%$ (mild); $50-79 \%$ (moderate); 30-49\% (severe); and < $30 \%$ (very severe). ${ }^{(9)}$ The severity (clinical stage) of COPD was determined according to the GOLD criteria $^{(9)}$ : post-bronchodilator $\mathrm{FEV}_{1}$; history of exacerbations in the last year; and symptoms such as dyspnea (measured by modified Medical Research Council dyspnea scale or COPD Assessment Test). On the basis of those criteria, each patient was categorized as having COPD that was at GOLD stage I, II, III, or IV. ${ }^{(9)}$ We evaluated COPD prognosis using the Body mass index, airflow Obstruction, Dyspnea, and Exercise capacity (BODE) index, stratifying the patients into four quartiles, the fourth being the most severe. ${ }^{(14)}$

Weight (in $\mathrm{kg}$ ) was measured, with the patients wearing light clothing, on a digital electronic scale (Toledo do Brasil, São Bernardo do Campo, Brazil) with a maximum capacity of $200 \mathrm{~kg}$ and an accuracy of $50 \mathrm{~g}$. Height $(\mathrm{m})$ was measured while the patients were standing with their back straight, heels together, and arms at their sides. On the basis of the BMI, the patients were classified as underweight (BMI $<22$ $\mathrm{kg} / \mathrm{m}^{2}$ ), normal weight (BMI $\geq 22$ and $<27 \mathrm{~kg} / \mathrm{m}^{2}$ ), or overweight/obese (BMI $\geq 27 \mathrm{~kg} / \mathrm{m}^{2}$ ), according to the categories established by Lipschitz et al., ${ }^{(15)}$ which are the most suitable for use in middle-aged and elderly individuals.

For the assessment of body composition, all patients underwent dual-energy X-ray absorptiometry (DXA) in a whole-body scanner (Lunar Prodigy; GE Medical Systems, Madison, WI, USA), used in conjunction with enCORE 2002 software (GE Medical Systems). The software provides data about lean body mass (bone mass plus fat-free mass), bone-free lean mass (lean mass minus fat-free mass), fat mass, and bone mineral density.

\section{Densitometric diagnosis of sarcopenia}

The criteria for a diagnosis of sarcopenia by DXA were initially defined by Baumgartner et al. ${ }^{(16)}$ in a study involving a large sample of elderly individuals in the state of New Mexico. However, using those criteria, the authors found that the prevalence of sarcopenia was underdiagnosed, probably due to the high proportions of overweight and obese individuals in the population studied. Newman et al.(17) proposed new methods for defining sarcopenia, by adjusting height and the appendicular lean mass (ALM) by the fat mass, which resulted in prevalence rates that were higher than those obtained with the former criteria. ${ }^{(17,18)}$ However, those authors found that the former criteria continued to be superior for diagnosing sarcopenia in underweight patients. In two recent studies conducted in Brazil, Domiciano et al. ${ }^{(19)}$ and Figueiredo et al. ${ }^{(20)}$ compared the two sets of criteria and concluded that the cut-off BMI value of $22 \mathrm{~kg} / \mathrm{m}^{2}$ defined the choice of criteria to be used for the densitometric diagnosis of sarcopenia.

For the purpose of the densitometric diagnosis of sarcopenia, we used both systems of determining ALM: using the skeletal muscle index (SMI), calculated as ALM (in $\mathrm{kg}$ ) relative to height squared in meters (ALM/ height ${ }^{2}$ ), with cut-off values of $7.26 \mathrm{~kg} / \mathrm{m}^{2}$ and $5.45 \mathrm{~kg} /$ $\mathrm{m}^{2}$ for men and women, respectively, hereafter referred to as the Baumgartner criteria(16); and calculating ALM (in $\mathrm{kg}$ ) relative to height in meters and adjusted for total body fat mass (in $\mathrm{kg}$ ), hereafter referred to as the Newman criteria. ${ }^{(17)}$ The residuals of the regression were used in order to identify individuals with a lean mass lower than the value predicted for a given fat mass (given by an equation derived from the model). A positive residual would indicate a relatively muscular individual, whereas a negative residual would indicate an individual with sarcopenia. The equations derived from the model were as follows:

\section{for men}

$$
\begin{aligned}
& A L M(\text { in } \mathrm{kg})=-28.15+27.49 \times \text { height }(\text { in } \mathrm{m})+ \\
& 0.1106 \times \text { fat mass (in } \mathrm{kg} \text { ) } \\
& \text { for women } \\
& A L M(\text { in } \mathrm{kg})=-19.78+20.00 \times \text { height (in } \mathrm{m})+ \\
& 0.1554 \times \text { fat mass (in } \mathrm{kg} \text { ) }
\end{aligned}
$$

The 20th percentile of the distribution of residuals was used as the cut-off value for the diagnosis of sarcopenia, according to the ALM adjusted for fat 
mass, as previously defined. ${ }^{(17,18)}$ In our patient sample, that cut-off value corresponded to residuals of -2.021 for men and -1.082 for women. To make the densitometric diagnosis of sarcopenia, we applied the Baumgartner criteria for individuals with a BMI < $22 \mathrm{~kg} / \mathrm{m}^{2}$ and the Newman criteria for individuals with a $B M I \geq 22 \mathrm{~kg} / \mathrm{m}^{2}$.(21)

\section{Statistical analysis}

Data are presented as mean $\pm S D$, except where otherwise specified. All statistical analyses were performed with the SPSS Statistics software package, version 20.0 (IBM Corporation, Armonk, NY, USA). For the variables evaluated, the normality of the data distribution was evaluated with the Kolmogorov-Smirnov test. For comparisons of quantitative variables between two groups, we used the Student's t-test for independent samples or the nonparametric Mann-Whitney test. For comparisons among three or more groups, we used one-way ANOVA and the least significant difference test for multiple comparisons or the nonparametric Kruskal-Wallis test. In the preliminary statistical analysis, we used Fisher's exact test and the chi-square test to assess the association between two qualitative variables. Values of $p<0.05$ were considered statistically significant.

For multivariate analysis, we used logistic regression, considering sarcopenia as the response (dependent) variable and the following as explanatory (independent) variables: age ( $\leq 67$ or $>67$ years), female gender, GOLD stage III or IV, BODE quartile 3 or 4 , and current smoking. For each variable, in the presence of the other variable included in the model, we tested the null hypothesis that the probability of sarcopenia is equal for the two classifications of the variable (lack of association between the variable and sarcopenia), versus the alternative hypothesis of different probabilities. We calculated the $p$ values of the statistical tests, as well as odds ratios with their corresponding $95 \%$ confidence intervals.

\section{RESULTS}

Of the 96 patients evaluated, 5 were excluded because they did not perform all of the required tests. Therefore, the final sample comprised 91 patients (50 women and 41 men), with a mean age of $67.4 \pm 8.7$ years and a mean BMI of $25.8 \pm 6.1 \mathrm{~kg} / \mathrm{m}^{2}$. Twenty-five patients $(27.4 \%)$ were classified as normal weight, $28(30.7 \%)$ were classified as underweight, and 38 $(41.7 \%)$ were classified as overweight. The overall mean percentage of total body fat mass was $32.3 \pm$ $11.7 \%(37.8 \pm 15.8 \%$ in women and $25.6 \pm 7.1 \%$ in men; $p=0.000)$, and the overall mean SMI was 6.57 $\pm 1.1(6.17 \pm 5$ for women and $7.05 \pm 5.3$ for men, $p$ $=0.000)$. The mean smoking history was $60 \pm 41.4$ pack-years. Sixteen patients (17.6\%) were current smokers at enrollment in the study.

On the basis of the $\mathrm{FEV}_{1}$ values, the degree of obstruction was classified as mild in $16(17.6 \%)$ of the patients, moderate in $33(36.3 \%)$, severe in 29 $(31.9 \%)$, and very severe in $13(14.3 \%)$. Among the 91 patients evaluated, COPD was classified as GOLD stage I in $15(16.5 \%)$, as GOLD stage II in 22 $(24.2 \%)$, as GOLD stage III in $34(37.4 \%)$, and as GOLD stage IV in 20 (22\%). Stratified by the BODE index, 36 patients (39.6\%) were in the first quartile, $29(31.9 \%)$ were in the second quartile, $15(16.5 \%)$ were in the third quartile, and $11(12.1 \%)$ were in the fourth quartile.

We found that BMI did not correlate significantly with FEV $_{1}(p=0.509)$, GOLD stage $(p=0.114)$, or BODE quartile $(p=0.114)$. Sarcopenia was diagnosed in 36 patients (39.6\%): 16 women and 20 men. When we stratified that result by BMI, we found that sarcopenia was present in $5(20.0 \%)$ of the 25 normal weight patients, $23(82.1 \%)$ of the 28 underweight patients, and $8(21.1 \%)$ of the 38 overweight patients. Figure 1 shows the number of patients with sarcopenia, by BMI, according to the set of criteria used in making the diagnosis. There were no significant differences in the prevalence of sarcopenia in relation to gender ( $p$ $=0.276)$, age $(p=0.309)$, or smoking history ( $p=$ $0.464)$. The mean SMI was $5.86 \pm 0.7$ in the patients with sarcopenia ( $5.38 \pm 0.42$ in women and $6.25 \pm 0.57$ in men), compared with $7.03 \pm 1.0$ in those without (6.54 \pm 0.89 in women and $7.81 \pm 0.77$ in men), the difference between the two groups being significant ( $p<0.001$ ). As can be seen in Table 1, the patients with sarcopenia also showed lower BMI $(p<0.001)$, lower percentage of total body fat $(p=0.01)$, and lower total lean mass $(p<0.001)$.

There was no association between the prevalence of sarcopenia and the severity of COPD, as determined by GOLD stage and $\mathrm{FEV}_{1}$ (Figures $2 \mathrm{~A}$ and $2 \mathrm{~B}$ ). There was a tendency toward an association between the prevalence of sarcopenia and the BODE quartile ( $p=$ $0.06)$. As depicted in Figure $3 A, 11$ patients $(30.5 \%)$ were in the first quartile, $9(31 \%)$ were in the second, $8(60 \%)$ were in the third, and $9(63.6 \%)$ were in the fourth. Figure 3B shows that the prevalence of sarcopenia among the patients in quartile 3 or 4 was $61.4 \%$, significantly higher than the $30.7 \%$ seen among those in quartile 1 or 2 ( $p=0.009 ;$ OR $=3.89 ; 95 \%$ $\mathrm{CI}: 1.21-12.46)$. The multivariate analysis showed that, regardless of age, gender, GOLD stage, and smoking status, the BODE index was significantly associated with sarcopenia (Table 2).

\section{DISCUSSION}

In our sample of COPD patients, there was a high prevalence of DXA-diagnosed sarcopenia, which was found to correlate with a poor prognosis. In patients with COPD, various factors have been shown to be associated with a worse prognosis, a higher number of hospitalizations, and shorter survival; chief among such factors is changes in body composition. ${ }^{(4)}$ Low BMI has been associated with acute exacerbations, mortality, and loss of lean mass in COPD patients. ${ }^{(5)}$ In 
the present study, we confirmed that a loss of lean body mass is associated with lower BMI in COPD patients. However, we did not find BMI to be associated with COPD severity or a worse prognosis, which is in agreement with the findings of recent studies demonstrating that reduced lean mass is a better predictor of mortality in COPD patients than is low BMI alone, the former reducing survival by up to $50 \%$. ${ }^{(22)}$

In our study, the overall prevalence of sarcopenia was $39.6 \%$, which is consistent with the literature on COPD patients, in which the reported prevalence is $20-40 \%$. $^{(52)}$ Cesari et al. ${ }^{(23)}$ diagnosed sarcopenia in $30 \%$ of the COPD patients evaluated; when the authors adjusted for fat mass, that rate rose to $42.5 \%$, a difference that was primarily attributed to the increased proportion of obese patients diagnosed. When we applied the Baumgartner criteria, we diagnosed sarcopenia in 37 patients (40.6\%), compared with only 19 patients $(21.0 \%)$ when we applied the Newman criteria. That was mainly due to the fact that the mean BMI in our sample was lower than that reported in

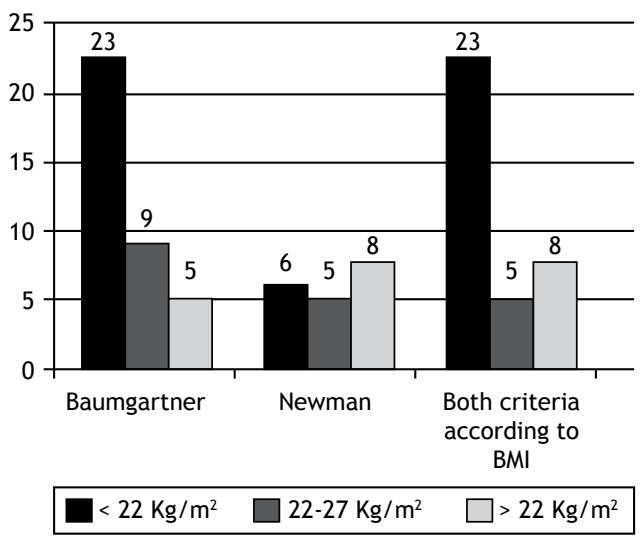

Figure 1. Number of patients with sarcopenia, by BMI, depending on the set of criteria used for the diagnosis: (left) the criteria by Baumgartner et al. ${ }^{(16)}$ in all patients; (center) the criteria by Newman et al. ${ }^{(17)}$ in all patients; and (right) the criteria by Baumgartner et al. ${ }^{(16)}$ for patients with a BMI $<22 \mathrm{~kg} / \mathrm{m}^{2}$ and the criteria by Newman et al. ${ }^{(17)}$ for patients with a BMI $\geq 22 \mathrm{~kg} / \mathrm{m}^{2}$. the other studies cited. For overweight and obese patients, adjusting for fat mass (i.e., applying the Newman criteria) was especially important, because it increased the prevalence of sarcopenia by $8 \%$ over that obtained when the Baumgartner criteria were applied. This demonstrates the importance of making this adjustment, which can prevent underdiagnosis.

The loss of lean body mass in patients with COPD has previously been shown to be associated with lower $\mathrm{BMI},{ }^{(6)}$ and we confirmed that. However, sarcopenia also occurs in approximately $20 \%$ of normal-weight, overweight, and obese patients. One study showed that a decrease in muscle mass occurs in $21 \%$ of normal-weight patients with $\mathrm{COPD}_{,}{ }^{(24)}$ and another

\section{(A)}

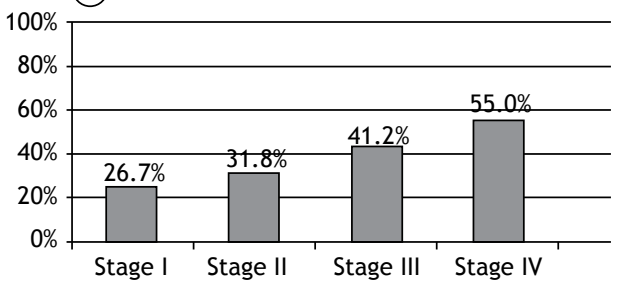

(B)

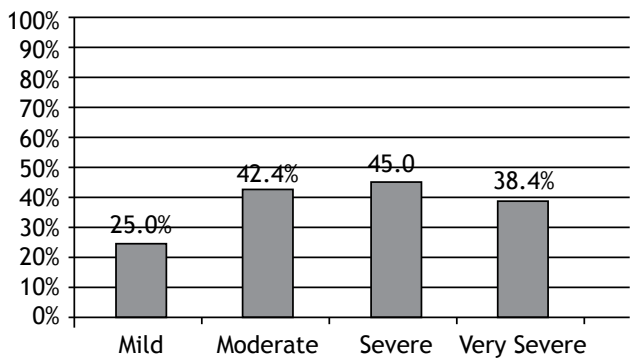

Figure 2. Prevalence of sarcopenia, diagnosed with dualenergy X-ray absorptiometry, among COPD patients ( $N$ = 91), by COPD severity (GOLD stage, in A) and degree of obstruction $\left(\mathrm{FEV}_{1}\right.$, in $\left.\mathrm{B}\right)$. Sarcopenia did not correlate significantly with GOLD stage $(p=0.305)$ or $F_{1}(p=$ $0.599)$. Degree of obstruction $\left(\mathrm{FEV}_{1}\right)$ : Mild $(\geq 80 \%)$; Moderate (50-79\%); Severe (30-49\%); and Very severe $(<30 \%)$.

Table 1. Differences between COPD patients with and without sarcopenia. ${ }^{a}$

\begin{tabular}{|c|c|c|c|}
\hline Variable & $\begin{array}{c}\text { Sarcopenia } \\
(n=36)\end{array}$ & $\begin{array}{l}\text { No sarcopenia } \\
\quad(n=55)\end{array}$ & $\mathbf{p}$ \\
\hline Age, years & $68.6 \pm 10.4$ & $66.6 \pm 7.46$ & 0.309 \\
\hline $\mathrm{BMI}, \mathrm{kg} / \mathrm{m}^{2}$ & $22.2 \pm 4.9$ & $28.2 \pm 5.6$ & $<0.001^{*}$ \\
\hline$\%$ Total BF & $28 \pm 14.2$ & $35.1 \pm 8.8$ & $0.01^{*}$ \\
\hline \multicolumn{4}{|l|}{ Lean mass, kg } \\
\hline Arms & $4.6 \pm 1.2$ & $3.9 \pm 1.0$ & $0.003^{*}$ \\
\hline Legs & $11.1 \pm 2.0$ & $13.6 \pm 3.2$ & $<0.001^{*}$ \\
\hline Total & $37.4 \pm 6.4$ & $44.1 \pm 9.3$ & $<0.001^{*}$ \\
\hline \multicolumn{4}{|c|}{ Skeletal muscle index ${ }^{\mathrm{b}}$} \\
\hline All patients & $5.86 \pm 0.7$ & $7.03 \pm 1.0$ & $<0.001^{*}$ \\
\hline Women & $5.38 \pm 0.42$ & $6.25 \pm 0.57$ & $<0.001^{*}$ \\
\hline Men & $6.54 \pm 0.89$ & $7.81 \pm 0.77$ & $<0.001^{*}$ \\
\hline
\end{tabular}

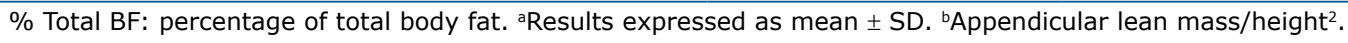


showed that $10-15 \%$ of COPD patients with a normal or high BMI have sarcopenia. ${ }^{(25)}$

Cigarette smoking is one of the mechanisms involved in the increased protein catabolism in COPD, as demonstrated in various epidemiological association studies on smoking and sarcopenia. ${ }^{(26)}$ Although there is controversy in the literature, one study demonstrated an association between smoking history and a loss of lean mass in COPD patients, ${ }^{(27)}$ whereas others have shown no such association. ${ }^{(28,29)}$ In the present study, we observed no association between smoking history and sarcopenia. One possible explanation for that finding is that patients with COPD show a high, persistent inflammatory state, with elevated levels of TNF- $\alpha$, which is involved in the physiopathology of sarcopenia, independently of the smoking history. ${ }^{(27)}$

In our sample of COPD patients, we found that a diagnosis of sarcopenia correlated with lower BMI, a reduction in the overall percentage of body fat, lower total lean mass, and the SMI. These findings are consistent with those of other studies of sarcopenia in patients with and without COPD, ${ }^{(30,31)}$ an annual reduction in muscle mass of $1-2 \%$ over 50 years having been shown to occur in COPD patients. ${ }^{(32)}$ A loss of
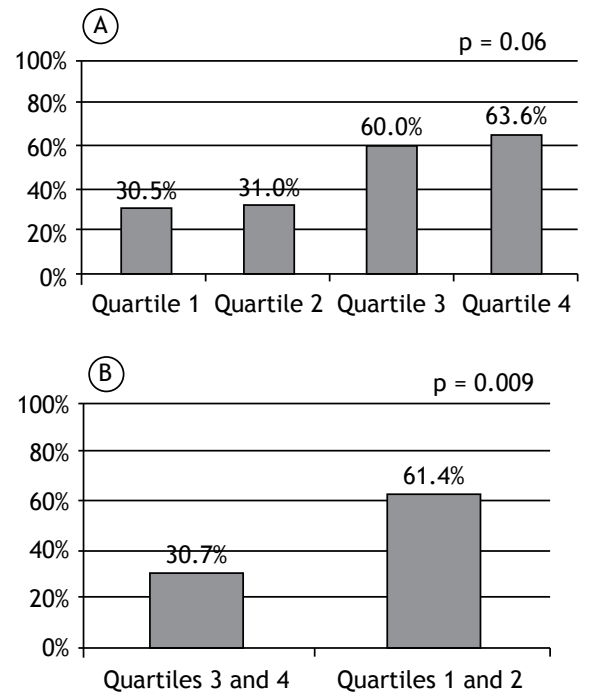

Figure 3. Proportion of patients diagnosed with sarcopenia by densitometry according to the quartiles of the Body mass index, airflow Obstruction, Dyspnea, and Exercise capacity (BODE) prognostic index, grouped by quartile (in A) and pooled (in $B$ ) into a less severe group (quartiles 1 and 2 ) and a more severe group (quartiles 3 and 4 ). lean body mass occurs by several mechanisms, such as TNF- $\alpha$-mediated motor neuron death, hormonal changes, nutritional status, and an increase in inflammatory factors. In our study, we detected no increase in the prevalence of sarcopenia with advancing age, which is in agreement with the findings of other studies of COPD. ${ }^{(33,34)}$ One possible explanation for this is that the severity of the disease and the elevated levels of inflammatory cytokines, present from the onset of COPD, contribute to a greater loss of lean mass, regardless of age. ${ }^{(35)}$

In the present study, neither the GOLD stage nor the degree of obstruction $\left(\mathrm{FEV}_{1}\right)$ was found to correlate with a diagnosis of sarcopenia. The number of patients studied and the distribution of the severity grades could explain that lack of correlation. In contrast with our findings, Ischaki et al. ${ }^{(36)}$ showed that, in COPD patients, a greater loss of lean body mass translates to greater disease severity, as quantified by GOLD criteria and $\mathrm{FEV}_{1}$. However, those authors assessed body composition using bioelectrical impedance analysis, which is less reliable than is DXA. ${ }^{(16)}$ In another recent study, lower lean mass was also associated with worse $\mathrm{FEV}_{1}$, although, again, body composition was assessed by bioelectrical impedance analysis. ${ }^{(37)}$

The BODE index, a prognostic parameter, considers exercise capacity, which can affect lean mass. We observed a trend toward a higher prevalence of sarcopenia among COPD patients in the higher BODE quartiles, and there was a statistically significant difference between those in the lower quartiles and those in the higher quartiles. In our multivariate analysis, the BODE index was significantly associated with sarcopenia, which was more prevalent among the patients with a worse prognosis (in quartile 3 or 4). To our knowledge, there have been no other studies investigating this association. A reduction in lean mass leads to exercise intolerance, which has been described as an essential factor for impairing quality of life, increasing the frequency of exacerbations/ hospital admissions, and increasing mortality. ${ }^{(4)}$ This confirms that sarcopenia is associated with a worse prognosis in COPD.

One limitation of our study is that we did not assess muscle strength. However, various studies have demonstrated a correlation between reduced lean body mass and decreased muscle strength. ${ }^{(38)}$ In addition, this limitation was likely offset by the fact

Table 2. Multivariate analysis in which sarcopenia was the dependent variable.

\begin{tabular}{lllll}
\hline Variable & \multicolumn{1}{c}{ Reference } & $\mathbf{p}^{*}$ & OR & 95\% CI \\
Age & $\leq 67$ years & 0.055 & 2.80 & $1.06-7.37$ \\
Gender & Female & 0.266 & 1.69 & $0.66-4.31$ \\
Clinical stage & GOLD stage III or IV & 0.744 & 1.19 & $0.41-3.42$ \\
Smoking status & Current smoking & 0.138 & 2.57 & $0.73-9.13$ \\
BODE index & Quartile 3 or 4 & $0.02^{*}$ & 3.89 & $1.21-12.46$ \\
\hline
\end{tabular}

GOLD: Global Initiative for Chronic Obstructive Lung Disease; and BODE: Body mass index, airflow Obstruction,

Dyspnea, and Exercise capacity. *Wald test (logistic regression) level of significance, $p<0.05$. 
that we applied the BODE index, which takes exercise capacity into account.

The results of the present study demonstrate that the prevalence of sarcopenia, as diagnosed by DXA, which is currently considered the gold standard method, was high in a sample of patients with COPD. Ours was a pioneering study in that we correlated the prevalence of sarcopenia with the BODE index quartile. The impairment and loss of lean mass are common and worrisome; as COPD extrapulmonary manifestations, they cause a reduction in exercise capacity. This can also result in even more pronounced loss of muscle mass, thus initiating a vicious cycle. Therefore, early diagnosis of sarcopenia, through the analysis of body composition, can facilitate the implementation of interventions aimed at preventing the deterioration of lean body mass and improving quality of life in patients with COPD.

\section{REFERENCES}

1. Eagan TM, Aukrust P, Ueland T, Hardie JA, Johannessen A, Mollnes $T E$, et al. Body composition and plasma levels of inflammatory biomarkers in COPD. Eur Respir J. 2010;36(5):1027-33. http://dx.do org/10.1183/09031936.00194209

2. Maltais F. Body composition in COPD: looking beyond BMI. Int J Tuberc Lung Dis. 2014;18(1):3-4. http://dx.doi.org/10.5588/ ijtld.13.0868

3. Vilaró J, Ramirez-Sarmiento A, Martínez-Llorens JM, Mendoza T, Alvarez M, Sánchez-Cayado N, et al. Global muscle dysfunction as a risk factor of readmission to hospital due to COPD exacerbations. Respir Med. 2010;104(12):1896-902. http://dx.doi.org/10.1016/j. rmed.2010.05.001

4. Schols AM, Broekhuizen R, Weling-Scheepers CA, Wouters EF. Body composition and mortality in chronic obstructive pulmonary disease. Am J Clin Nutr. 2005;82(1): 53-9. http://dx.doi.org/10.1016/j. rmedu.2005.09.028

5. Marquis $K$, Debigaré $R$, Lacasse $Y$, LeBlanc $P$, Jobin J, Carrier $G$ Maltais F. Midthigh muscle cross-sectional area is a better predictor of mortality than body mass index in patients with chronic obstructive pulmonary disease. Am J Respir Crit Care Med. 2002;166(6):809-13. http://dx.doi.org/10.1164/rccm.2107031

6. Polkey $\mathrm{Ml}$, Moxham J. Attacking the disease spiral in chronic obstructive pulmonary disease. Clin Med. 2006;6(2):190-6. http:// dx.doi.org/10.7861/clinmedicine.6-2-190

7. Santilli V, Bernetti A, Mangone M, Paoloni M. Clinical definition of sarcopenia. Clin Cases Miner Bone Metab. 2014;11(3):177-80. http:// dx.doi.org/10.11138/ccmbm/2014.11.3.177

8. Franssen FM, Sauerwein HP, Rutten EP, Wouters EF, Schols AM Whole-body resting and exercise-induced lipolysis in sarcopenic [corrected] patients with COPD. Eur Respir J. 2008:32(6):146671. Erratum in: Eur Respir J. 2009;33(4):947. http://dx.doi org/10.1183/09031936.00014008

9. Global Initiative for Chronic Obstructive Lung Disease [homepage on the Internet]. Bethesda: GOLD [cited 2015 Feb 27]. Global Strategy for the Diagnosis, Management, and Prevention of Chronic Obstructive Lung Disease (Revised 2011). [Adobe Acrobat document, 90p.]. Available from: http://www.goldcopd.org/uploads/ users/files/GOLD_Report_2011_Feb21.pdf

10. Prignot J. Quantification and chemical markers of tobacco-exposure. Eur J Respir Dis. 1987;70(1):1-7.

11. Ferris BG. Epidemiology Standardization Project (American Thoracic Society). Am Rev Respir Dis. 1978:118(6 Pt 2):1-120.

12. Jones PW, Harding G, Berry P, Wiklund I, Chen WH, Kline Leidy $N$. Development and first validation of the COPD Assessment Test. Eur Respir J. 2009;34(3):648-54. http://dx.doi org/10.1183/09031936.00102509

13. BALKE B. A SIMPLE FIELD TEST FOR THE ASSESSMENT OF PHYSICAL FITNESS. REP 63-6. Rep Civ Aeromed Res Inst US. 1963 Apr:1-8

14. Celli BR, Cote CG, Marin JM, Casanova C, Montes de Oca M, Mendez RA, et al. The body-mass index, airflow obstruction, dyspnea, and exercise capacity index in chronic obstructive pulmonary disease. N Engl J Med. 2004;350(10):1005-12. http://dx.doi.org/10.1056/ NEJMoa021322

15. Lipschitz DA. Screening for nutritional status in the elderly. Prim Care. 1994;21(1):55-67

16. Baumgartner RN, Koehler KM, Gallagher D, Romero L, Heymsfield $\mathrm{SB}$, Ross RR, et al. Epidemiology of sarcopenia among the elderly in New Mexico. Am J Epidemiol. 1998;147(8):755-63. http://dx.doi. org/10.1093/oxfordjournals.aje.a009520
17. Newman AB, Kupelian V, Visser M, Simonsick E, Goodpaster B, Nevitt $M$, et al. Sarcopenia: alternative definitions and associations with lower extremity function. J Am Geriatr Soc. 2003;51(11):1602-9. http://dx.doi.org/10.1046/j.1532-5415.2003.51534.x

18. Delmonico MJ, Harris TB, Lee JS, Visser M, Nevitt M, Kritchevsky $\mathrm{SB}$, et al. Health, Aging and Body Composition Study. Alternative definitions of sarcopenia, lower extremity performance, and functional impairment with aging in older men and women. J Am Geriatr Soc. 2007;55(5):769-74. http://dx.doi.org/10.1111/j.1532 5415.2007.01140.x

19. Domiciano DS, Figueiredo CP, Lopes JB, Caparbo VF, Takayama $L$, Menezes PR, et al. Discriminating sarcopenia in communitydwelling older women with high frequency of overweight/obesity: the São Paulo Ageing \& Health Study (SPAH). Osteoporos Int 2013;24(2):595-603. http://dx.doi.org/10.1007/s00198-012-2002-1

20. Figueiredo CP, Domiciano DS, Lopes JB, Caparbo VF, Scazufca M, Bonfá E, Pereira RM. Prevalence of sarcopenia and associated risk factors by two diagnostic criteria in community-dwelling older men: the São Paulo Ageing \& Health Study (SPAH). Osteoporos Int. 2014;25(2):589-96. http://dx.doi.org/10.1007/s00198-013-2455-x

21. Cruz-Jentoft AJ, Baeyens JP, Bauer JM, Boirie Y, Cederholm T, Land $F$, et al. Sarcopenia: European consensus on definition and diagnosis: Report of the European Working Group on Sarcopenia in Older People. Age Ageing. 2010;39(4):412-23. http://dx.doi.org/10.1093/ ageing/afq034

22. Wagner PD Possible mechanisms underlying the development of cachexia in COPD. Eur Respir J. 2008;31(3):492-501. http://dx.doi. org/10.1183/09031936.00074807

23. Cesari M, Pedone C, Chiurco D, Cortese L, Conte ME, Scarlata S, et al. Physical performance, sarcopenia and respiratory function in olde patients with chronic obstructive pulmonary disease. Age Ageing 2012;41(2):237-41. http://dx.doi.org/10.1093/ageing/afr167

24. Bolton $C E$, Ionescu AA, Shiels KM, Pettit RJ, Edwards PH, Stone $\mathrm{MD}$, et al. Associated loss of fat-free mass and bone mineral density in chronic obstructive pulmonary disease. Am J Respir Crit Care Med. 2004;170(12):1286-93. http://dx.doi.org/10.1164/rccm.200406$7540 \mathrm{C}$

25. Vestbo J, Prescott E, Almdal T, Dahl M, Nordestgaard BG, Andersen $T$, et al. Body mass, fat-free body mass, and prognosis in patients with chronic obstructive pulmonary disease from a random population sample: findings from the Copenhagen City Heart Study. Am J Respir Crit Care Med. 2006;173(1):79-83. http://dx.doi. org/10.1164/rccm.200506-969oc

26. Rom O Kaisari S, Aizenbud D Reznick AZ Sarcopenia and smoking: a possible cellular model of cigarette smoke effects on muscle protein breakdown. Ann N Y Acad Sci. 2012;1259:47-53. http:// dx.doi.org/10.1111/j.1749-6632.2012.06532.x

27. Eagan TM, Gabazza EC, D'Alessandro-Gabazza C, Gil-Bernabe P, Aok S, Hardie JA, et al. TNF- $\alpha$ is associated with loss of lean body mass only in already cachectic COPD patients. Respir Res. 2012;13:48. http://dx.doi.org/10.1186/1465-9921-13-48

28. Tanni SE, Pelegrino NR, Angeleli AY, Correa C, Godoy I. Smoking status and tumor necrosis factor-alpha mediated systemic inflammation in COPD patients. J Inflamm (Lond). 2010;7:29. http:// dx.doi.org/10.1186/1476-9255-7-29

29. Iwaniec UT, Fung YK, Cullen DM, Akhter MP, Haven MC, Schmid $M$. Effects of nicotine on bone and calciotropic hormones in growing female rats. Calcif Tissue Int. 2000:67(1):68-74. http://dx.doi. org/10.1007/s00223001099

30. Rutten EP, Calverley PM, Casaburi R, Agusti A, Bakke P, Celli B, et 
al. Changes in body composition in patients with chronic obstructive pulmonary disease: do they influence patient-related outcomes? Ann Nutr Metab. 2013;63(3):239-47. http://dx.doi.org/10.1159/000353211

31. Verhage TL, Heiidra Y, Molema J, Vercoulen J, Dekhuiizen R Associations of muscle depletion with health status. Another gender difference in COPD? Clin Nutr. 2011;30(3):332-8. http://dx.doi. org/10.1016/.j.lnu.2010.09.013

32. Kim TN, Choi KM. Sarcopenia: definition, epidemiology, and pathophysiology. J Bone Metab. 2013;20(1):1-10. http://dx.doi. org/10.11005/jbm.2013.20.1.1

33. Agustí $A$, Barberà JA, Wouters EF, Peinado VI, Jeffery PK. Lungs, bone marrow, and adipose tissue. A network approach to the pathobiology of chronic obstructive pulmonary disease. Am J Respir Crit Care Med. 2013;188(12):1396-406. http://dx.doi.org/10.1164/ rccm.201308-1404PP

34. Hopkinson NS, Tennant RC, Dayer MJ, Swallow EB, Hansel TT, Moxham J, et al. A prospective study of decline in fat free mass and skeletal muscle strength in chronic obstructive pulmonary disease.
Respir Res. 2007;8:25. http://dx.doi.org/10.1186/1465-9921-8-25

35. Ferrucci L, Penninx BW, Volpato S, Harris TB, Bandeen-Roche K, Balfour $J$, et al. Change in muscle strength explains accelerated decline of physical function in older women with high interleukin-6 serum levels. J Am Geriatr Soc. 2002;50(12):1947-54. http://dx.doi. org/10.1046/j.1532-5415.2002.50605.x

36. Ischaki E, Papatheodorou G, Gaki E, Papa I, Koulouris N, Loukides S Body mass and fat-free mass indices in COPD: relation with variables expressing disease severity. Chest. 2007;132(1):164-9. http://dx.doi. org/10.1378/chest.06-2789

37. Abbatecola AM, Fumagalli A, Spazzafumo L, Betti V, Misuraca C Corsonello $A$, et al. Body composition markers in older persons with COPD. Age Ageing. 2014;43(4):548-53. http://dx.doi.org/10.1093/ ageing/aft196

38. Hansen RD, Raja C, Aslani A, Smith RC, Allen BJ. Determination of skeletal muscle and fat-free mass by nuclear and dual-energy $\mathrm{x}$-ray absorptiometry methods in men and women aged 51-84 y (1-3). Am J Clin Nutr. 1999;70(2):228-33. 